\title{
Lingüística Textual: Quo Vadis?
}

(Textlinguistics: Quo vadis?)

\author{
Ingedore Grunfeld Villaça KoCH \\ (Universidade Estadual de Campinas)
}

ABSTRACT: This paper aims to discuss the future - and the proper survival of Textlinguistics this millenium, and the challenges it has to face in order to contribute to the development of Human Sciences in a new era.

KEY-WORDs: Textlinguistics; Human Sciences; Tasks for the next millenium.

REsUMO: Este artigo tem por objetivo discutir o futuro - e a própria sobrevivência da Lingüistica Textual neste milênio e os desafios que terá de enfrentar para contribuir para o desenvolvimento das Ciências Humanas numa nova era.

PaLAVRas-CHAVE: Lingüítica Textual; Ciências Humanas; Tarefas para o novo milênio.

\section{Introdução}

“Quo vadis, Textlinguistik?” É com estas palavras que Heinemann \& Viehweger (1991) encerram o capítulo introdutório de seu livro Textlinguistik: Eine Eiführung, intitulado "O que é e o que pretende a Lingüística Textual?"

Por seu turno, Antos (1997) propõe que, para se obter uma resposta a essa questão, se parta da pergunta: "O que deve e o que pode explicar a L.T.?". Segundo ele, para se chegar a uma resposta conclusiva, importa saber o que a L.T. tem-se proposto explicar, desde o seu surgimento, ou melhor, com qual conceito de texto vem trabalhando. O que pode verificar é que várias concepções de texto têm acompanhado a história dessa disciplina, levando-a a assumir formas teóricas diversas, entre as quais se podem destacar: 
1. texto como frase complexa (fundamentação gramatical)

2. texto como expansão tematicamente centrada de macroestruturas (fundamentação semântica)

3. texto como signo complexo (fundamentação semiótica)

4. texto como ato de fala complexo (fundamentação pragmática)

5. texto como discurso "congelado"-produto acabado de uma ação discursiva (fundamentação discursivo-pragmática)

6. texto como meio específico de realização da comunicação verbal (fundamentação comunicativa)

7. texto como verbalização de operações e processos cognitivos (fundamentação cognitivista)

Poderíamos nos perguntar, também, dizem Antos \& Tietz (1997), se, nestes trinta anos de existência, a Lingüística Textual desempenhou apenas um papel de "hóspede" da Lingüística, talvez um modismo como tantos outros, ou, então, se ela se tornou uma ciência integrativa de várias outras ciências (Retórica, Estilística, Teoria dos Gêneros, Teoria da Argumentação, Narratologia etc.), vindo a constituir uma "Ciência ou Teoria da Linguagem” (van Dijk, 1978)? Ou se ela faz parte integrante do domínio estabelecido da lingüística, quem sabe até do seu núcleo central? E, se for assim, quais seriam os prognósticos que se podem fazer quanto ao seu futuro? E indagam ainda: será que todas essas perguntas surgem apenas porque a Lingüística textual entrou numa fase de consolidação de tal forma espetacular que questôes sobre a justificação de sua existência estariam tão fora de propósito quanto, por exemplo, questões sobre a Semântica, a Fonologia ou a Sintaxe?

O que se pôde, com efeito, verificar é que, na época do surgimento da Lingüística Textual, em função do conceito de texto então majoritário, a maioria dos estudiosos se dedicava à análise transfrástica e/ou à construção de gramáticas do texto, de modo que o objeto precípuo de estudo era a coesão (isto é, a propriedade de hang together, de cohere), por isso, muitas vezes equiparada à coerência, já que ambas eram vistas como qualidades ou propriedades do texto.

Uma das tônicas da década de 80 foi justamente a ampliação significativa do conceito de coerência, quando, adotando-se uma perspectiva pragmático-enunciativa, passou-se a postular que não se trata de mera propri- 
edade ou qualidade do texto em si, mas de um fenômeno muito mais amplo: a coerência se constrói, em dada situação de interação, entre o texto e seus usuários, em função da atuação de uma complexa rede de fatores, de ordem lingüística, sócio-cognitiva e interacional. Vieram a público diversas coletâneas sobre o tema (Charolles, Petöfi \& Sözer, 1983; Neubauer, 1983; Petöfi, 1986; Sözer, 1985; Conte, Petöfi \& Sözer, 1989, entre várias outras), além de artigos e obras individuais. Também no Brasil, as pesquisas sobre coesão e coerência textuais tiveram grande desenvolvimento, frutificando em uma série de obras sobre o assunto. Podem-se mencionar, entre muitos outros, os trabalhos de Marcuschi (1983), Koch (1987,1989, 1992); Koch \& Travaglia (1989, 1990); Fávero (1991) e Bastos (1985). Além disso, outros critérios de textualidade passaram a ser objeto das pesquisas sobre o texto, tais como informatividade, situacionalidade, intertextualidade, intencionalidade, aceitabilidade (cf. Beaugrande \& Dressler, 1981), contextualização, focalização, consistência e relevância.

É também nessa década que se delineia com vigor a abordagem cognitiva do texto, especialmente a partir dos estudos de Van Dijk e Kintsch, que vai ganhando cada vez mais terreno e passa a dominar a cena no início da década de 90, agora, porém, com forte tendência sóciocognitivista.

\section{Situação atual}

A partir desse momento, com o desenvolvimento cada vez maior das investigações na área de cognição, as questões relativas ao processamento do texto, em termos de produção e compreensão, às formas de representação do conhecimento na memória, à ativação de tais sistemas de conhecimento por ocasião do processamento, às estratégias sócio-cognitivas e interacionais nele envolvidas, entre muitas outras, passaram a ocupar o centro dos interesses de diversos estudiosos do campo. A título de exemplo, podem-se destacar as obras de Heinemann \& Viehweger (1991), Koch \& Oesterreicher (1990), Nussbaumer (1991), Adam (1990 e 1993), de van Dijk (1994, 1995,1997), entre várias outras. No Brasil, pode-se citar uma série de trabalhos desenvolvidos por Marcuschi e por Koch (Marcuschi \& Koch, 1998; Koch \& Marcuschi, 1998; Marcuschi, 1998, 1999; Koch, 1997, 1998, 1999), para citar apenas alguns. 
Além da ênfase que se vem dando aos processos de organização global dos textos, assumem importância particular as questões de ordem sóciocognitiva, que envolvem, evidentemente, as da referenciação, inferenciação, acessamento ao conhecimento prévio etc.; o tratamento da oralidade e da relação oralidade/escrita; e o estudo dos gêneros textuais, este agora conduzido sob outras luzes - isto é, a partir da perspectiva bakhtiniana, voltando, assim, a questão dos gêneros a ocupar lugar de destaque nas pesquisas sobre o texto e revelando-se hoje um terreno extremamente promissor.

A questão da referenciação textual, por exemplo, vem sendo objeto de pesquisa de um grupo de autores franco-suíços (Projeto Cognisciences), entre os quais se podem destacar Apothéloz, Kleiber, Charolles, Berrendonner, Reichler-Béguelin, Chanêt, Mondada e D. Dubois. Estes autores têm dedicado especial interesse a questões como a criação dos "objetos-de-discurso", a anáfora associativa, sua conceituação e sua abrangência, as operaçōes de nominalização e suas funções, entre várias outras com elas de alguma forma relacionadas. O principal pressuposto destas pesquisas é o da referenciação como atividade discursiva, como é postulado também em Marcuschi \& Koch,1998a; Koch \& Marcuschi, 1998b; Marcuschi, 1998; Koch, 1998). Desta forma, de conformidade com Mondada \& Dubois (1995) e Apothéloz \& Reichler-Béguelin (1995:228ss), postula-se que a referência é sobretudo um problema que diz respeito às operaçōes efetuadas pelos sujeitos à medida que o discurso se desenvolve; e que o discurso constrói os "objetos" a que faz remissão ("objetos-de-discurso"), ao mesmo tempo que é tributário dessa construção.

O estudo do texto falado, que envolve também questôes de ordem sócio-cognitiva e interacional, ganha, neste momento, uma projeção cada vez maior e toma rumos diferentes dos da Análise da Conversação, como se pode verificar na obra de Koch \& Oesterreicher (1990) e em inúmeros projetos voltados para a descrição da modalidade oral da língua, tanto na Europa, como na América. É o caso, no Brasil, do Projeto de Gramática do Português Falado, idealizado por Castilho, que tem como uma de suas vertentes o estudo da organização textual-interativa no português falado no Brasil, esta coordenada por Koch. É o caso, também, do Projeto NURC/ SP, coordenado por Preti, e do NELFE - Núcleo de Estudos Lingüísticos sobre Fala e Escrita, coordenado por Marcuschi. 
Quanto à questão dos gêneros, acima mencionada, cabe ressaltar a releitura que vem sendo feita da obra de Bakhtin (1953), na qual o autor apresenta a sua conceituação de gêneros do discurso. Além de obras importantes como, por exemplo, a de Tadros, na Inglaterra, e de autores da Escola Norte-americana, como Miller, Freedman, Coe e Bazerman, bem como, na França, a de Jean-Michel Adam (1993), destacam-se, nesse domínio, os trabalhos da equipe de Ciências da Educação da Universidade de Genebra, conduzidos por Bernard Schneuwly, Joachim Dolz e Jean-Paul Bronckart, que procedem a essa releitura com finalidades didáticas, isto é, do ponto de vista de suas aplicaçôes educacionais.

Este grupo, que considera o gênero como suporte das atividades de linguagem, define-o com base em três dimensōes essenciais: 1) os conteúdos e os conhecimentos que se tornam dizíveis a partir dele; 2) os elementos das estruturas comunicativas e semióticas partilhadas pelos textos reconhecidos como pertencentes a determinado gênero; 3 ) as configuraçōes específicas de unidades de linguagem, traços, principalmente, da posição enunciativa do enunciador, bem como dos conjuntos particulares de seqüências textuais e de tipos discursivos que formam sua estrutura. Estabelece, portanto, distinção entre gêneros, tipos discursivos e sequiências textuais (narrativas, expositivas, argumentativas), estas vistas como esquemas básicos que entram na constituição dos diversos gêneros e variam menos que estes em função das circunstâncias sociais. O gênero, assim definido, atravessa a heterogeneidade das práticas de linguagem e faz emergir toda uma série de regularidades no uso. São as dimensões partilhadas pelos textos pertencentes ao gênero que lhe conferem uma estabilidade de facto, o que não exclui, evidentemente, evoluçôes, por vezes, importantes.

\section{Perspectivas futuras}

Retomemos, agora, a questão: Qual será o futuro dos estudos sobre o texto? Ou, colocando a questão de forma mais pessimista, pode-se dizer que a Lingüística Textual tem algum futuro?

Verificou-se que, desde seu aparecimento até hoje, a Lingüística Textual percorreu um longo caminho e vem ampliando e modificando a cada passo seu espectro de preocupações. De uma disciplina de inclinação primeiramente gramatical (análise transfrática, gramáticas textuais), depois 
pragmático-discursiva, ela transformou-se em disciplina com forte tendência sócio-cognitivista: as questóes que ela se coloca, neste final de século, são as relacionadas com o processamento sócio-cognitivo de textos escritos e falados.

Uma primeira questão que se coloca é como ela se irá posicionar diante de novas perspectivas, e, em especial, com relação a novos meios de representação do conhecimento, como é o caso, por exemplo, do hipertexto, suporte lingüístico-semiótico hoje intensamente utilizado para estabelecer interaçóes virtuais desterritorializadas, caracterizado fundamentalmente pela ausência de linearidade, traço inerente aos textos tradicionais. Que conseqüências terá isto para a delimitação de seu domínio? Que novos procedimentos metodológicos ela deverá desenvolver?

Com relação a todas essas questões posta com relação ao futuro da disciplina, gostaria aqui de mencionar duas obras que, neste final de século, apontam aberturas que considero de grande relevância:

1) A nova obra de R. de Beaugrande: "New Foundations for a Science of Text and Discourse: Cognition, Communication, and Freedom of Access to Knowledge and Society" (Novos Fundamentos para uma Ciência do Texto e do Discurso: Cognição, Comunicação e Liberdade de Acesso ao Conhecimento e à Sociedade) - publicada em 1997, em que o autor, além de fazer uma excelente retrospectiva da lingüística textual desde suas origens até os nossos dias, aponta as suas perspectivas e tarefas futuras. Afirmando que "hoje, a lingüistica de texto é provavelmente melhor definida como o subdomínio lingüistico de uma ciência transdisciplinar do texto e do discurso", o autor passa a definir o texto como "um evento comunicativo no qual convergem açôes lingüisticas, cognitivas e sociais", postulando como motto da lingüística textual de nossos dias: "Um texto não existe como texto, a menos que alguémo processe como tal". Desta forma, os princípios de textualização deixam de ser vistos como critérios ou padrões que um texto deve satisfazer, mas como um conjunto de condições que conduz cognitivamente à produção de um evento interacionalmente comunicativo. Isto é, os sete padrões de textualidade propostos em Beaugrande $\&$ Dressler (1981) não são critérios que permitem identificar as fronteiras entre um texto e um não texto, mas sim as condiçôes para uma ação lingüística, cognitiva e social na qual eles operam como modos de conectividade em níveis diversos, mas interrelacionados. 
Uma Lingüística Textual como ciência do discurso e do texto deveria, pois, montar seus modelos com base em uma agenda mínima (Beaugrande, 1997: 144-145), que consiste em: a) definição dos objetivos (por exemplo, "liberdade de acesso ao conhecimento e à sociedade através do discurso"); b) definição dos termos-chave e conceitos numa terminologia sistemática, com um uso consistente (termos vistos como centros de controle para a ativação global de conhecimentos sociais, discursivos cognitivos); c) acesso às atividades implicadas pela construção do modelo como ações cognitivas, discursivas e sociais (ações de identificação, conexão, experienciação, temporalização, espacialização, observação, mensuração, predição etc.).

2) O trabalho recente de Gerd Antos - "Texte als Konstitutionsformen von Wissen" (Textos como formas de constituição do conhecimento) - também publicado em 1997, in Antos \& Tietz (orgs.), Die Zukunft der Textlinguistik, na qual o autor defende a posição de que textos são, lingüística, conceptual e perceptualmente, formas de cognição social e que seu papel, no contexto da evolução do conhecimento, é o de constituir-se em ponto de partida e de chegada para ancoragem da Lingüística de Texto no quadro de uma teoria da evolução cultural. Antos, em sua argumentação, parte das seguintes premissas:

- A moderna evolução do conhecimento, com sua multiplicidade cultural, histórica e funcional, seria impossível sem a existência de textos, formas lingüísticas da constituição e organização do conhecimento complexo. Esquece-se, muitas vezes, que todo conhecimento coletivamente válido é sempre um conhecimento lingüisticamente constituído e, só desta forma, sociocognitivamente existente, como também o fato de que as formas de constituição textual necessitam elas mesmas desenvolver-se no curso da evolução da sociedade; ou seja, o que se pode (ou se permite) ser representado, por quais meios, gêneros, variedades ou estilos, de que maneira (entorno temporal ou espacial, modo etc.) está na dependência de tradições históricas e socioculturais.

- Os textos não são apenas meios de representação e armazenamento (arquivos) de conhecimento - portanto, não são apenas "realizações" lingǘsticas de conceitos, estruturas e processos cognitivos - mas sim formas básicas de constituição individual e social do conhecimento, ou seja, textos são lingüística, conceitual e perceptualmente formas de cognição social. 
Incluem-se aí todos os modos de uso comunicativo de formas coletivas do conhecimento, que necessitam ser considerados como formas de distribuição comunicativa do conhecimento: somente assim, nas sociedades modernas, o conhecimento coletivo complexo pode reivindicar validade e relevância social. Isto é, os textos são, por um lado, formas de elaboração, diferenciação e estruturação de conhecimento e, por outro, formas de controle, crítica e transformação, bem como de constituição e apresentação ("retoricamente" orientada) do conhecimento, visando ao que, em termos bakhtinianos, se denominaria uma comunicação responsiva ativa. Todo o conhecimento declarativo de nossa sociedade é (com exclusão daquele que se traduz em números ou fórmulas, primariamente lingüístico, ou melhor, conhecimento textualmente fundado.

- Pressupondo-se uma visão processual e dinâmica do conceito de texto, os textos, pelo fato de só poderem estruturar o conhecimento de forma seletiva, são, por um lado, apenas "estaçôes intermediárias" para a criação de outros textos; e, por outro lado, pontos de partida para a assimilação textualmente baseada do conhecimento ("texto na memória"). É por isso que, com plena consciência, Antos prefere falar de textos, no plural, ressaltando que o plural deve sinalizar que cada texto individual, apesar de - ou justamente em razão de - sua força constitutiva do conhecimento, depende da ativação de outros domínios deste (preconcebidos, ativação de pressuposições, inferências, saber intertextual etc.).

A partir de tais premissas, Antos apresenta doze teses, dentre as quais gostaria de destacar as seguintes:

- Os textos constituem formas de organização do conhecimento complexo pelo fato de fornecerem formatos para a arquitetura lingüistica (verbal) do conhecimento socio-cognitivo relevante. A arquitetura formal dos textos constitui a organização lingüística, conceitual e perceptual do conhecimento. É por esta razão que os extos, de uma perspectiva constitutiva do conhecimento - ainda que em sentido fraco - podem ser concebidos como teorias sobre aspectos do mundo. Compreendidos como formas de cognição social, os textos estruturam universos de conhecimento social relevante: por isso é que se pode dizer, de uma perspectiva socioconstrutivista, que textos são modelos sobre mundos, isto é, sobre complexos de estados de coisas estruturados e selecionados sob dada perspectiva. Em outras palavras, é por meio de textos que tais mundos são criados (ou a cada nova recepção e reprodução, re-criados). 
- Determinados aspectos da realidade social são criados por meio da representação dessa realidade e só assim ganham validade e relevância social. Os textos não só tornam visível o conhecimento, mas sobretudo tornam-no sócio-cognitivamente existente. Para tanto, a seletividade no processamento textual desempenha papel relevante: escolha do tema, do médium, da perspectiva, da focalização ou da organização figura/fundo, balanceamento entre dito e não-dito (ou seja, a relação entre pressupostos, explícitos e inferíveis), a escolha da modalidade (verdade, verossimilhança, ficcionalidade), bem como o emprego de recursos estilísticos etc. Todos estes aspectos interrelacionam-se com a arquitetônica textual.

- Os textos são condição de possibilidade de se tornar o conhecimento explícito, de segmentá-lo, diferenciá-lo, pormenorizá-lo, de inseri-lo em novos contextos, permitir sua reativação, de testá-lo, avaliá-lo, corrigi-lo, reestruturá-lo, tirar novas conclusōes a partir daquilo que já é compartilhado e de representar lingüisticamente, de forma nova, novas relações situacionais e sociais.

Antos ressalta três aspectos decisivos da concepção por ele proposta:

1) Textos como modelos de mundos dão origem por definição, enquanto Modelos de algo', a concatenações (Zuammenhänge) de sentido coerentes.

2) Como modelos, eles incorporam 'conhecimento sobre algo', caso contrário, permaneceriam proposicionalmente vazios.

3) Textos como modelos precisam ser, via de regra, formulados lingüisticamente, para poder preencher pressupostos cognitivos e comunicativos.

Daí resulta que, tomando por base o conceito de texto assim estabelecido, é possível pleitear uma Lingüística de Texto fundamentada numa Teoria da Evolução Cultural, cujo objeto será explicitar a evolução cultural da geração (e re-geração), organização e transmissão de formas de cognição social e de formas de uso social do conhecimento (inclusive formas de distribuição comunicativa). Ou seja, cabe-lhe por tarefa explicitar todo e qualquer aspecto da evolução (hoje universal) do conhecimento que diga respeito a modelos e formas lingüísticas, conceptuais e perceptuais do conhecimento, bem como aos modos de seu emprego comunicativo. 


\section{Considerações finais}

Os textos, como formas de cognição social, permitem ao homem organizar cognitivamente o mundo. E é em razão dessa capacidade que são também excelentes meios de intercomunicação, bem como de produção, preservação e transmissão do saber. Determinados aspectos de nossa realidade social só são criados por meio da representação dessa realidade e só assim adquirem validade e relevância social, de tal modo que os textos não apenas tornam o conhecimento visível, mas, na realidade, sociocognitivamente existente. A revolução e evolução do conhecimento necessita e exige, permanentemente, formas de representaçáo notoriamente novas e eficientes.

Assim, a Lingüística Textual, com esta nova concepção de texto, parece ter-se tornado um entroncamento, para o qual convergem muitos caminhos, mas que é também o ponto de partida de muitos deles, em diversas direções. Esta metáfora da Lingüística de Texto como estação de partida e de passagem de muitos - inclusive novos - desenvolvimentos abre perspectivas otimistas quanto a seu futuro, como parte integrante não só da Ciência da Linguagem, mas das demais ciências que têm como sujeito central o ser humano.

A Ciência ou Lingüística do Texto sente necessidade de intensificar sempre mais o diálogo que já há muito vem travando com as demais Ciências - e não só as Humanas! -, transformando-se numa "ciência integrativa" (Antos \& Tietz, 1997). É o caso, por exemplo, do diálogo com a Filosofia da Linguagem, a Psicologia Cognitiva e Social, a Sociologia Interpretativa, a Antropologia, a Teoria da Comunicação, a Literatura, a Etnometodologia, a Etnografia da Fala e, mais recentemente, com a Neurologia, a Neuropsicologia, as Ciências da Cognição, a Ciência da Computação e, por fim, com a Teoria da Evolução Cultural. Torna-se, assim, cada vez mais, um domínio multi - e transdisciplinar, em que se busca compreender e explicar esse objeto multifacetado que é o texto - fruto de um processo extremamente complexo de interação construção social de conhecimento e de linguagem. 


\section{REFERÊNCIAS BibLIOGRÁFicaS}

ADAM, J.M. (1990) Élements de Linguistique Textuelle. Liège: Mardaga. (1993) Les Textes: Types et Prototypes. Lausanne: Nathan.

AnTos, G. (1997) Texte als Konstitutiosformen von Wissen Thesen zu einer evolutiostheoretischen Begründung der Textlinguistik. In: ANTOS, G. \& H. TIETZ (orgs.) Die Zukunft der Textlinguistik. Traditionen, Transformationen, Trends. Tübingen: Niemeyer.

ApotнÉLOz, D. (1995) Nominalisations, réferents clandestins et anaphores atypiques. In: BerRendonNer, A. \& M-J Reichler-BEGUelin (eds.): 143-173.

Apothéloz, D. \& M-J. Reichler-Béguelin (1995) Construction de la référence et stratégies de désignation. In: BERRENDONNER, A. E M-J. REICHLER-BEGUELIN (eds.): 227-271.

Bakhtin, M. (1953) Estética da Criação Verbal. São Paulo: Martins Fontes, 1992.

BAstos, L. K. X. (1985) Coesão e Coerência em Narrativas Escolares Escritas. Campinas: Editora da UNICAMP.

Beaugrande, R. de (1997) New Foundations for a Science of Text and Discourse: Cognition, Communication, and Freedom of Access to Knowledge and Society. Norwood, New Jersey: Alex.

\& Dressler, W.U. (1981) Einfhrung in die Textlinguistik. Tübingen, Niemeyer.

BerRendonner, A. \& M-J. Reichler-BÉGuelin (eds.) (1995) Du Sintagme Nominal aux Objets-de-discours. Neuchâtel: Université de Neuchâtel: 143-173.

Charolles, M., Petöfi, J. \& Sözer, e. (eds.) (1983) Research in Text Connexity and Text Coherence. Hamburgo: A. Survey.

Charolles, M. (1964) Anaphore associative, stéréotype et discours. In:

SCnedecker; Charolles; Kleiber; David, L'Anaphore associative. Paris: Klincksieck, 1994: 67-92.

(1989) Coherence as a principle in the interpretability of discourse. In: W. Heydrich, F. Neubauer, J. Petöfi (eds.), Connexity and Coherence, Berlim: De Gruyter.

PetöFI, J. \& SöZer, E. (eds.) (1989) Text and Discourse Connectedness. Hamburg: Bruske.

FÁvero, L. L. \& I. G. V. KoCH (1983) Lingüistica Textual: Introdução. São Paulo: Cortez. 
KInTSCH, W. \& T. van DijK (1975) Comment on rappelle et on résume des histoires. Langage, 40: 298-116.

(1978) Toward a model of text comprehension and production. Psychological Review, 85: 369-394.

Koch, I.G.V. (1989) A Coesão Textual. São Paulo: Contexto.

(1992) A inter-ação pela Linguagem. São Paulo: Contexto.

(1997) O Texto e a Construção dos Sentidos. São Paulo: Contexto. \& L. C. Travaglia (1989) Texto e Coerência. São Paulo: Cortez. (1990) A Coerência Textual. São Paulo: Contexto.

(1999) A referenciação textual como estratégia cognitivo interacional. In: BARros, K.S.M. (org.) Produção Textual: Interação, Processamento, Variação. Natal: EDUfuRn, 69-80.

\& L.A. MARCusCHI (1998) Processos de referenciação na produção discursiva. D.E.L.T.A. 14 esp: 169-190.

KOCH, W. \& W. OESTERREICHER (1990) Gesprochene Sprache in der Romania: Französisch, Italienisch, Spanisch. Tübingen: Niemeyer MARCUSCHI, L. A. (1983) Lingüística de Texto: o que é e como se faz. Recife: Universidade Federal de Pernambuco, Série Debates 1.

\& I.G. V. KосH (1998) Processos de referenciação na produção discursiva. In: Abaurre, M.B. (org.) Gramática do Português Falado, vol. VIII, Campinas, Edunicamp/Fapesp, no prelo.

(1998) Aspectos lingüísticos, sociais e cognitivos na produção de sentido. Texto apresentado por ocasião do GELNE, 2-4 de setembro de 1998 (mímeo).

MondadA, L. \& Dubois, D. (1995) Construction des objets du discours et catégorisation : une approche des processus de référenciation. In: BERRENDONNER \& REICHLER-BÉGUELIN, op. cit., 273-305.

Neubauer, F. (ed.) (1983) Coherence in Natural Language Texts. Hamburgo: Buske. Nussbaumer, M. (1991) Was Texte sind und wie sie sein sollen. Tübingen: Niemeyer.

Schneuwly, B. De (1994). Genres e types de discours: considérations psychologiques et ontogénétiques. In: ReUTER (ed.) Actes du Colloque de l'Université Charles De Gaulle III, Les Intéractions Lecture-écriture. Neuchâtel: Peter Lang, pp. 155-73.

Sözer, E. (ed.) (1985) Text Connexity. Text Coherence. Aspects, methods, results. Hamburgo: Buske.

Tadros, A. (1985) Prediction in Text. ELR Monographs. Birmingham: University of Birmingham 
VAN DIJK, T.A. (1972) Some aspects of textgrammars. The Hague: Mouton. (1977) Text and Context. Londres: Longman. (1978) Tekstweteschap. Een Interdisciplinaire Inleidig. Utrecht.

(1979) Recalling and summarizing complex discourse. In: W.Burghardt \& K HölKer (eds.) Text processing. Berlim: deGruyter, $49-118$.

(1980) Macrostructures. Hillsdale, N.J.: Lawrence Erlbaum. (1997) Cognitive context models and discourse. (mímeo) \& KinTSCH, W. (1983) Strategies of Discourse Comprehension. New York: Academic Press. 